\title{
On farthest and simultaneous farthest points in Köthe spaces
}

\author{
SH. AL-SHARIF
}

\section{ABSTRACT.}

Let $X$ be a real Banach space and $G$ be a closed bounded subset of $X$. For $x \in X$, we set $\rho(x, G)=\sup \{\|x-y\|: y \in G\}$. The set $G$ is called remotal if for any $x \in X$, there exists $g \in G$ such that $\rho(x, G)=\|x-g\|$. In this paper we show that for a separable remotal set $G \subset X$, the set $E(G)$ is remotal in $E(X)$, where $E(X)$ is the Köthe Bochner function space. Some other results are presented.

DEPARTMENT OF MATHEMATICS

YARMOUK UNIVERSITY

IRBID, JORDAN

E-mail address: sharifa@yu.edu. jo 